\title{
El nuevo orden internacional: ¿la pax americana?
}

\author{
Fco. Javier Ibisate
}

El título enuncia no la existencia sino la necesidad de un nuevo orden internacional, mientras que la pregunta cuestiona los principios éticos de una alternativa de paz que parece querer imponerse. En el lapso de tres anos ha cambiado sensiblemente el escenario del orden y de la paz internacional. Al finalizar en 1989 la guerra fría entre los dos bloques y sus superpotencias parecía iniciarse un nuevo milenarismo de paz y de prosperidad económica. Tras el dernumbe del muro de BerIIn el Este caminaba hacia el Oeste y el Oeste invertiria en el Este. La Nueva Europa o el "hogar común" que to llamara Gorbachov, con sus 800 millones de habitantes, ampliaba el espacio de un gran mercado común que relegaria al olvido el recuerdo de dos décadas de estanflación. La carrera armamentistica se transformaria en reconversión económica, y los regimenes totalitarios en democracias o socialdemocracias. El marco del nuevo modelo democrático seria la economia de mercado, con o sin el aditivo de social.

El cambio de escenarios significaba un cambio de civilizaciones y de poderes. Con el proceso de desarmamentización las dos superpotencias irian perdiendo su cualidad de superpotencias, en deudas que estaban por la misma carrera armamentistica. Con el desmantelamiento del Pacto de Varsovia y de la OTAN los tanques rusos tendrian que regresar para enfrentar el más serio problema de "la des-unión soviética", y los batallones-USA, acampados en Europa, regresarian-sin desfiles ni confetis-a su lugar de origen. Renacia una nueva Europa ante el claro declive de las superpotencias, obligadas a conquistar Europa por la vía de la inversión y de la competitividad económica. Es claro que esta alternativa estaba cerrada a las economias del Este, su- 
midas en el peor derrumbe político y económico, y cuya única salida era dejarse conquistar y anexionar por las economias del Oeste.

También los EE.UU. habian quedado parcialmente rezagados frente a la tecnología japonesa y europea, especialmente la alemana. El nuevo centro del poder económico pivoteaba en Tokio, Bonn y Bruselas, sede de la Comunidad Europea. Con cierto humor se comentaba que Japón le estaba cobrando con creces a los EE.UU. las dos bombas de Hirósima-Nagaski por medio de su balanza comercial anualmente favorable. Luego de una guerra militar ganada, una guerra comercial perdida. Pero no es fácil para una superpotencia aceptar el paso de las civilizaciones y dejar de ser el centro del poder y de las decisiones internacionales.

El conflicto del Golfo-Pérsico ha sido el triste hecho histórico que ha servido simultáneamente para devolver la euforia y la primogenitura a los EE.UU., al mismo tiempo que ha destanteado y dividido la proyectada unión europea. Pero también aqui la victoria militar ha puesto en cuestionamiento los valores éticos de la guerra, una "ética sin moral", asl como sus consecuencias económicas y sociales para el nuevo orden intemacional. Frente a esta guerra, que en mes y medio descargó un potencial destructivo similar al de la segunda guerra mundial sobre la Alemania nazi, se han levantado voces de protesta y de acusación. "La guerra es un horror para todos" dijo J.K. Galgraith el pasado mes de marzo en Madrid y anadió: "Se pudo evitar el conflicto del Golfo-Pérsico; pero hay gente en el mundo que se sigue excitando con el uso de las armas y que necesitan un enemigo"'

La euforia del triunfo que confirma a los EE.U' ' como la gran superpotencia militar sin opositores no diluye los remordimientos de conciencia que, algo en EE.UU. y mucho más en Europa, han generado la cronología del aun imprevisible conflicto del Medio Oriente. Se ha podido ganar una batalla, pero también se ha podido perder la guerra por la paz y por un nuevo orden internacional más justo. No está fuera de lugar dedicar un tiempo de reflexión al tema de la guerra y del nuevo orden mundial situados en un escenario similar al del lejano Golfo-Pérsico.

\section{Una Invasión segulda de otra Invasión}

No se trata de hacer una cronología de los hechos sino una reflexión sobre la "lógica de la guerra". La guerra-invasión de Kuwait

1. El Pals. 10-3-91; p. 6). Como la mayorla de citas se sacan de este diario, se indicará entre paréntesis la fecha y página correspondiente. 
Iniclada sorpresivamente por Sadam Hussein el 2 de agosto de 1990, ¿convierte en legítima, lícita y moral la guerra-invasión de Irak aprobada por el Consejo de Seguridad de la ONU, a instancias norteamerlcanas, y ejecutada a partir del 17 de enero-1991? Es interesante que al responder esta pregunta los razonamientos se estén convirtiendo en remordimientos. Obviamente es condenable la anexión de Kuwait por parte de Sadam Hussein, asi como la amenaza de Irak de iniciar una guerra contra Israel con armas A-B-C (atómicas, biolóligas, químicas). Los principios del derecho internacional condenan estos hechos imperlalistas y justifican el derecho de autodefensa. Para magnificar y legitimar la represalia se calificó a Sadam Hussein como el Hitler del Medio Oriente. Antes de la guerra militar se desató la "guerra de los insultos". G. Bush era el demonio-satán de Occidente y Sadam Hussein el Hitler mesiánico contemporáneo. Los calificativos escondían a la vez motivaciones religioso-culturales y políticas.

Aqui comienzan las dudas y cavilaciones. No es en agosto de 1990 cuando Sadam Hussein se muestra, por primera vez, un dictador sin escrúpulos; las matanza de kurdos y shiies son anteriores al conflicto del Golfo-Pérsico y fueron verdaderas violaciones a los derechos humanos de minorias y mayorias nacionales. En aquellos momentos no se alzaron las voces de protesta desde el occidente europeo o norteamericano. ¿Se puede explicar y justificar este silencio porque Sadam Hussein estaba librando la gran guerra de perdedores contra Iran y el Ayatola Jomeini, el enemigo visceral del occidente europeo y de norteamérica? ¿Se puede explicar el silencio porque "el enemigo de mi enemigo es mi amigo"? Todas son violaciones de los derechos humanos y no debe aplicarse una doble moral.

Además escándalos contemporáneos tienen causales más antiguas y del mismo género que se critica. W. Pfaff, de Harvard, en su artículo sobre "Un nuevo orden internacional ilusorio", comenta. "Nos olvidamos con demasiada facilidad del hecho de que el conflicto no es producto de la ambición individual o de la política de una nación, Irak, sino que tiene origenes culturales e históricos en el dominio de la sociedad Islámica por parte de Europa, desde la época de la conquista de Indonesia por los holandeses en el siglo XVII y la conquista de la India por Gran Bretaña en el siglo XVIIII. La rabia que está explotando Sadam Hussein -y el Ayatola Jomeini o sus sucesores- y el coronel Gadafi, tienen sus orígenes en más de tres siglos de dominación extranjera. Desde 1950 tres estados islámicos han reaccionado frente a esto con éxito. Argelia contra Francia; Egypto, con Nasser en Suez, y con Sadam en el ataque de 1973 sobre Israel; e Iran con Jomeinl. La guerra del Golfo-Pérsico es el cuarto esfuerzo. Sólo un loco podrla 
pensar que será el último". En esta zona y en el presente siglo las potencias occidentales han dejado recuerdos de tono imperialista. Francia y el Reino Unido colonizaron desde 1919 algunas de estas regiones. Luego las companias petrolíferas extrajeron pingues beneficios, trazaron fronteras artificiales e impusieron como reyezuelos a antiguos jefes de tribu. El Gobierno de los EE.UU. sigue interviniendo en la zona decisivamente desde el conflicto de Suez, y protege con voluminosas ayudas a Israel, una fortaleza militar, silenciando y vetando el retiro de los territorios confiscados de Golán que ordenaran las Naciones Unidas. Todo este pasado colonialista ha querido ser utilizado y mezclado por Sadan Hussein para justificar su invasión de Kuwait. De acuerdo que el pasado no sirve de justificación de la invasión presente, pero el pasado sl debe estar presente a la hora de modelar el nuevo orden político del conflictivo medio oriente.

W. Pfaff continúa: "Resulta muy difícil creer que puede haber una resolución ordenada de las tensiones que existen actualmente, no sólo entre los paises islámicos y occidente, sino también entre todas las sociedades empobrecidas y débiles y las naciones privilegiadas. La distancia entre ellas es cada vez mayor. Nos han prometido un nuevo orden mundial para después de la guerra del Golfo-Pérsico. Sin embargo, el hombre prudente apostaria por un nuevo desorden" (5-2-91; p.17).

Si toda invasión de un pals extranjero es condenable llama la atención que los primeros en rasgarse las vestiduras fueran el o los gobernantes norteamericanos quienes algo recientemente hicieron similares barrabasadas en Grenada, Panamá..., sin encomienda alguna de las Naciones Unidas. ¿Será que Kuwait, además de pals invadido, es un feudo rico en petróleo? Debajo de la carátula de los derechos humanos parecen esconderse argumentos económicos: con la anexión de Kuwait, Irak controlaría la mitad de la producción del petróleo del medio Oriente, y esto si era un atentado a los derechos económicos de Occdiente, que habia trazado unas fronteras bastante artificiales en dicha zona.

La crítica se vuelve poco a poco también contra el Consejo de Seguridad de la ONU. ¿Son ellos los jueces más calificados para condenar una invasión armada, en sí misma condenable? ¿No se les puede devolver el boomerang? Sucede que los cinco miembros permanentes del Consejo de Seguridad (EE.UU., URSS., Francia Gran Bretana y China) son precisamente los que encabezan la lista mundial de exportación de armas. Por anadidura, dos de ellos son palses totalitaristas de partido único, que no han brillado mucho por el respeto 
a los derechos humanos nacionales y fuera de su pais... La invasión de Kuwait es condenable, pero también son condenables qulenes prevlamente intercambiaron armas por petróleo o armas por sangre, allmentando la guerra de perdedores entre Irán e Irak, la misma Invasión de Kuwait y los conflictos por venir; ya se está haciendo sabrosos contratos de armas contra petróleo con otros paises de esa zona. No deja de ser desconcertante -como lo veremos más adelanteque la reconstrucción de postguerra en el Medio Oriente y el surtido de armas, se transformen en un catalizador de la esperada recuperación en cierto lugar del Occidente. Estamos más de acuerdo con el profesor emérito de Harvard., J. K. Galbraith, cuando dice: "la guerra es un horror para todos".

\section{Contra la "Ióglca de la guerra"}

El título está prestado del articulo que recientemente escribió el Dr. Jürgen Haberman, catedrático de la Universidad Libre de Francfort. En Alemania, que no envió tropas pero sl aportó su contribución a los gastos de guerra, este conflicto ha sacudido algunas conciencias. A Sadam Hussein se le califió como el nuevo Hitler, por su invasión y por su antisemitismo; pero la invasión y las amenazas a Israel se hacia con armamento convencional y quimico, en parte vendido por Alemania Occldental. Al condenar las consecuencias hay un proceso de autocondenación o autoculpabilidad compartida. Por anadidura, los alemanes inconformes comienzan a decir que no ha habido una unificación alemana sino una anexión de la Alemania del Este por la Alemania Federal. También en Francia, el Ministro de Defensa, M. Chevenement, dimitió con la justificación de que la lógica de la guerra aparta cada día más a las naciones en guerra de los fines y líneas marcadas por las Naciones Unidas. Por su parte. Espana hizo de acólito de los EE.UU. cediendo alguna base a los aviones norteamericanos y facilitando dos fragatas para avituallamiento de tropas, de las cuales una quedó varada en el camino. Los espanoles califican su cruzada como "un Lepanto sin fe". La URSS de Gorbachov intentó mediar hasta el último minuto para buscar salidas pollticas al horror de la guerra...

Estas breves referencias sirven a recordar que la participación europea en la guerra de respuesta, lidereada por EE.UU. y comparsada por los herederos de la $\mathrm{M}$. Tathcher, ha generado laudables arrepentimientos y fructuosas reflexiones sobre la "ética de la guerra", y que pudieran semos de provecho en un país conocedor de la guerra y de los horrores de la guerra 
Un corresponsal de EI Pals hizo la siguiente pregunta a N. Bobbio, filósofo italiano: -Tal como están ahora mismo las cosas (26-2-91) ¿considera que la guerra debe pararse inmediatamente o seguir hasta el final? - "Hay que parar la guerra" contestó Bobbio; "no hacerlo, serla irresponsablen.- ¿ ¿Cómo es que este filósofo $\rightarrow$ padre de la filosofla neopositiva italiana - junto con el profesor de filosofla de la universidad de Franfort, J. Habermann, llegan a similares conclusiones?- Se parte de la pregunta ritual: ¿se puede hacer la guerra?; "poder" no significa ser posible, sino ser licito. ¿Se debla hacer la guerra? SI es cierto que una acción debida debe también ser licita, no es igualmente verdad que una acción deba hacerse por el simple hecho de que es llcita. Entra aqul en consideración "la ética de la responsabilidad", que juzga las acciones, no en base a to que las precede, sino en base a sus consecuencias. La ética de la responsabilidad exige que antes de poner la guerra en marcha se valoren, con la máxima seriedad, las posibles consecuencias".

Antes del 15 de enero-91 estaban sobre la mesa todos los argumentos normativos". La resolución de la ONU, que autorizaba una acción militar contra Irak, estaba amparada por los principios del derecho internacional y justificada como la percepción colectiva del derecho de autodefensa frente al agresor... Los principios que en esa situación justificaban, también en caso necesario una guerra son indiscutibles...; lo controvertido es su aplicación".

Para magnificar los antecedentes se magnifico en 10 posible la capacidad destructiva de Irak; se decla que este cuarto ejército posela y amenazaba con las más destructivas armas modemas (A_B_C) en manos de un dictador y mesiánico imperialista. Influyó en ello la llamada guerra de los insultos. Lo que no se intentó decir es que muchas de estas armas no servlan sin la asistencia técnica extranjera, como parece que lo comprobaron los hechos de guerra, a menos de suponer una conversión pacifista de Sadam Hussein. La magnificación de esta amenaza no diluye la magnitud real de la capacidad destructiva de Irak, al mismo tiempo que sive para justificar y acumular el mayor poder destructivo de las potencias occidentales, especialmente la norteamertcana, y detener la destrucción con la destrucción. Con ello la respuesta se irá convirtiendo en una exhibición de poder y en una amenazante lección para los paises inconformes del tercer mundo.

Aqul se sitúa la ética de la responsabilidad que pondera las consecuencias y los resultados de la acción a emprender. Se magnifica la amenaza para magnificar la respuesta. Pero el fin no justifica los medios, si por ligereza o por falta de buena voluntad no se preven las 
consecuencias. Esto nos llevaria a una tercera hipótesis: "las consecuencias habian sido previstas,pero se decidió no tenerlas en cuenta por razones de Estado. En este caso, sobre el juicio de si una acción se debe o no llevar a cabo, la ética de la responsabilidad no tiene nada que decir. El juicio sobre la posibilidad y el deber de la acción se dan en base a un principio completamente distinto: el fin justifica los medlos. Llegados a este punto las preguntas fundamentales son otras: ¿qué medios, qué fines, o mejor qué medios para qué fines? ¿Era posible obtener lo mismo con medios distintos, menos cruentos, menos destructivos, menos inhumanos, menos generadores de consecuencias slempre menos previsibles y por tanto, a diferencia del caso precedente, ya no corregibles?".

Con ocasión de este conflicto se ha repetido que la primera victima de la guerra es la verdad. La censura militar ha hecho los mejores esfuerzos para ocultar la verdad de la muerte. Nada de los efectos letales del machaqueo aéreo; se ha empleado una terminologia neutralizadora:" cazas invisibles, armas inteligentes, guerra limpia, operación quińrgica, efectos colaterales, misiones de ablandamiento..., destinadas a escamotear el hecho casi impensable de la destrucción de un pais oprimido e indefenso, desrealizando el mal y expulsando del lenguaje las palabras decisivas: petroleo y sangre. El control casi absoluto de la información televisiva mundial les ha permitido a su vez, mediante la programación cuidadosa del espectáculo abstracto de una video-guerra -soldados sonrientes y pulcros, ataques a objetivos lejanos, castillos de fuegos artificiales de efectos lenitivos y estéticos- hablar de Bagdad iluminada como un árbol de Navidad y anestesiar a millones de espoctadores con imágenes suaves y analgésicas" (16-3-91; p. 11).

"La guerra ha sucedido pues con estricto respeto al programa de destrucción masiva previsto por el general Schwarzkopf. No sabemos nada de la amplitud de la devastación; la sobredosis televisiva estaba más destinada a provocar la admiración - y por tanto el temor- hacia la tecnología de muerte norteamericana que a informar sobre los estragos de vidas humanas y en infraestructuras socio-económicas. Se sabe únicamente que Irak ha quedado destruido, que no se repondrá asi como asi de semejante tormenta y que ni la dirección iraqui ni la diplomacia de los aliados tienen interés en decir la verdad sobre la amplitud de la matanza... Pero algún dia habrá que hacer luz sobre todas las atrocidades de esta guerra electromecánica. $Y$ si el número de muertos iraquies se eleva como muchos observadores piensan -de 60.000 a 200.000 personas, nos daremos cuenta de que los temores del ex-ministro francés de Defensa, $M$. Chevenement, no eran fruto de estado de ánimo, sino de la más trágica lucidez. Digan lo que dlgan.... 
la opinión pública árabe no hará borrón y cuenta nueva. El resentimiento andará su camino, y todo hace suponer que las poblaciones que se han opuesto a la estrategia norteamericana no superarán el luto tranquilamente en el diván del psicoanalista" (14-3-91; p. 11).

Estos y otros muchos comentarios aparecidos en los rotativos europeos muestran que la censura militar norteamericana se equivoco si quiso tener éxito con su publicidad cazabobos. Al terminar la guerra la censura militar dilató el objetivo de sus cámaras para hacer ver la destrucción y la crueldad de Sadam Hussein en la persecución de kurdos y shiítas. ¿Por qué la censura militar no mostró las mismas crueldades y genocidios de Sadam Hussein, antes del conflicto, cuando él era el enemigo de mi enemigo? Una forma de acercarnos a la verdad de la muerte es hacer aqui una breve referencia al problema de la reconstrucción, sobre el que volveremos más adelante. Cifras preliminares adelantan que el Gobierno de Kuwait tendrá que invertir unos $\$ 100.000$ millones en los dos o tres primeros anos para reconstruir todo lo destruido; un volumen de destrucción que no capta el radar de nuestra imaginación, y que expresado comparativamente sobrepasa el monto del Plan Marshall, que en dólares de 1990 tuvo un valor de $\$ 70.000$ millones. En el caso de Irak, las primeras declaraciones valoran en unos $\$ 200.000$ millones los danos producidos por la aviación aliada. Pero al ir listando los danos físicos realmente causados, los reportes presentados en el mes de marzo duplican para ambos paises los costos de la reconstrucción. Volveremos sobre este punto preguntándonos por los mayores beneficiarios de todo el proyecto de la reconstrucción.

Estos datos de la destrucción física nos devuelven al cuestionamiento de la ética de las responsabilidades, porque debajo de estos escombros - al igual que bajo el bunker bombardeado- se esconden cientos de miles de vida humanas segadas. El Comité Internacional de la Cruz Roja declaró públicamente que "el derecho a escoger los métodos y los medios de guerra no es, en modo alguno, ilimitado. Están prohibidas armas que golpean indiferenciada y ciegamente, que danan desproporcionadamente a seres humanos y entorno. Incluso, aunque justifiquemos una intervención, no hay manera de acallar la pregunta de si se puede decir to mismo del modo y del alcance de esa guerra supertecnológica contra una población de 18 millones. ¿Las victimas causadas hasta hoy por la guerra están en relación justificable al mal que se quería evitar? - La ética de Estado utilizó la amenaza de ataque a Israel como una sólida razón para justificar la guerra contra el Hitler de Irak. En este sentido, la conducta de Israel, su paciente tolerancia para no aplicar ni siquiera el consejo biblico del "ojo por ojo y 
diente por diente" es laudable y contrasta con la conducta de quienes, on buena lógica de guerra, se sirvieron de la amenaza contra Israel para dar el primer paso hacia la destrucción de Irak.

J. K. Galbraith repite las mismas reflexiones que J. Haberman dejara aflorar desde Alemania; ambos a dos rehacen camino pasado senalando una de las causales bélicas, el floreciente comercio de las armas. "En Irak hemos estado luchando contra armas que fueron proporcionadas por la Unión Soviética, por Alemania, por Francia y -esto lo digo con mucho énfasis- por los Estados Unidos. Y la lección que - ospero que aprendarnos es que debemos parar el comercio de las armas"... - a la pregunta: ¿qué sensación ha dejado a usted esta guerra?, Galbraith responde: "Una de ellas es que ningún pais debe aproplarse de otro, esperando además que su acción sea aceptada por todo el mundo. También hemos comprobado que la ONU puede llegar - ser una organización efectiva y, en tercer lugar, debemos pensar que la guerra no sólo entrana el horror de la muerte para quienes ganan, olno también para quienes pierden. La guerra es un horror para todos. Esa es la sensación más dramática que produce un conflicto armado on los hombres. El recurso a la guerra debe ser el último recurso, y no debe ser tomado por razones económicas y políticas. Estoy seguro de que la prolongación efectiva del embargo pudo haber evitado tanta desgracia. Yo no hubiera querido jamás la guerra, pero todavia tenemos en este mundo gente impaciente a la que le sigue excitando la actlvidad militar" (10-3-91; p. 6).

Sabemos que varios presidentes de naciones europeas trataron de mediar hasta el último momento entre la amenaza de guerra y la torquedad mesiánica de Sadam Hussein. La persuasiva medicación de M. Gorvachov ante el Ministro de Asuntos Exteriores de Irak obedecería de acuerdo a Z. Brzezinski, ex-asesor militar de Jimmy Carter, - razones más bien políticas, con miras a mantener la buena imagen coviética en la zona y no permitir que el Medio Oriente sea complelamente dominado por los EE.UU. Para el ex-asesor militar de J. Carter pesan más las cavilaciones políticas que la visión sobre el nuevo orden mundial pueda tener el Premio-Nobel de la Paz. Pero al mismo tiempo Z. Brzezinski duda de que los EE.UU., estén preparados para cumplir ou papel de "policla global", que impone las normas a otra civilización, la islámica. "La única cuestión es qué hacer con nuestra aplastante preponderancia en la región. Lo que me preocupa es que los EE.UU. puedan no estar preparados para asumir las responsabilidades políticas necesarias que emanan de una victoria militar: la creación de una estructura de seguridad en la región completamente nueva, la promoción de una redistribución de la riqueza entre los árabes, el avance 
en el proceso de la paz árabe-israeli. La zona ha estado tan saturada de armamentos durante los últimos años, y los antagonismos políticos, étnicos y religiosos son tan enormes que se precisa una gran dedicación norteamericana para ayudar a resolver estos problemas. Sólo si asumimos estas responsabilidades podremos redimirnos completamente y hacer que hayan valido la pena todos los sufrimientos causados por la guerra" (7-3-91; p. 4).

Los EE.UU. asumieron o forzaron el mandato de las Naciones Unidas para ser los garantes del nuevo orden internacional, y con ello se asemejan el Prometeo mítico, que robó en el cielo el fuego de los dioses, lo trajo a la tierra y luego no podía apagarlo. Uno de los puntos de agenda debatidos es si la autorización del ataque a Irak fue una emanación de la ONU o una imposición de la superpotencia militar, de la misma manera que otras declaraciones de las Naciones Unidas fueron retardadas o vetadas por la misma superpotencia.

\section{El papel y el mandato de las Naclones Unidas}

Bajo el título de "El Nuevo Orden Internacional" Javier Pérez de Cuéllar, Secretario General de la ONU, sintetiza el papel histórico que esta institución ha jugado a lo largo del siglo-XX. Luego de las guerras mundiales $y$ en el contexto de la guerra fría las Naciones Unidas han reinvindicado los dos principios universales de la autodeterminación de los pueblos y el respeto a los derechos humanos. Para quien recuerda los azarosos esfuerzos del Secretario General tienen sentido las siguientes palabras, pronunciadas pocos dias antes de sus viajes: "Simultáneamente, el estallido de la crisis del Golfo-Pérsico ha subrayado la necesidad de lograr el retorno de la paz, no por el uso unilateral de las fuerzas, sino por la implicación de sanciones económicas u otras medidas, como lo indica la Carta".

Javier Pérez de Cuéllar reconoce que éste y tantos conflictos bélicos del tercer mundo tienen raíces históricas y sólo pueden limitarse por la acción concertada de las naciones". Los gérmenes de la guerra deben quedar eliminados en todas las zonas del planeta. Los niveles de armamento y de fuerzas deben quedar reducidos tanto a niveles globales como regionales... No amanecerá una nueva era sin que la debilidad y los defectos de la anterior desaparezcan. Además de los enconados conflictos políticos, una de las mayores fisuras de la vieja época es el incremento de la distancia existente entre las naciones ricas y las pobres, a causa de las fuerzas y presiones de la economia. En la nueva era habrá que desarrollar un marco para relaciones económicas y equitativas. Un mundo que no esté dividido por el telón 
de acero, pero sí por el telón de la pobreza no puede ser el mundo seguro al que todos aspiramos... La dinámica de los asuntos humanos slempre producirá nuevos puntos de choque y de fricción, pero habrá una via civilizada de resolverlos conforme a los mejores principios de la racionalidad humana. Esta es la promesa de las Naciones Unidas" (52-91; p. 13).

¿Por qué falló la promesa? Si para Javier Pérez de Cuéllar las Naciones Unidas tienen el gran papel de liderear y promocionar la paz y el orden internacional "como naciones unidas", el cuestionamiento levantado con el conflicto del Medio-Oriente es precisamente si la ONU, on su estructura y funcionamiento, es controlada por una minoria de naciones, es decir por intereses particulares nacionales. El citado exporto en política internacional W. Pfaff opina que "G Bush y sus asesores no han descrito todavia el nuevo orden de que habla el Presidente. El sehor Bush ha dicho simplemente que prevee un comportamiento internacional basado en las normas del derecho y en una mayor participación en el mantenimiento de la paz por parte de la ONU... En ol extranjero hay una idea diferente sobre el nuevo orden mundial. Se plensa que consistirá en que EE. UU., la única superpotencia, actúe como policia del mundo para defender los intereses de la democracia" $(5-2-91 ;$ p. 7) he aqui un ejemplo.

En la cronologia de este conflicto, oberva J. Goitisolo, escritor, se oucedieron rápidamente sensibles transformaciones del objetivo fijado por las Naciones Unidas. La primera resolución fue la condena de la in. vasión de Kuwait y la exigencia de la retirada incondicional iraqui. Luego la imposición del embargo al agresor $y$, sin darle tiempo de que surtiera efecto, su sustitución por el recurso eventual a la fuerza para llbrerar el emirato, derivando paulatinamente a la destrucción militar y económico de Irak y la caida de S. Hussein, sin atender los esfuerzos de mediación soviéticos, ni la aceptación por Bagdad de las condiciones aliadas, 10 que podrian haber salvado docenas de miles de vidas humanas. La conclusión de este escritor nos lleva al "triste papel de comparsa desempenado por la Comunidad Europea y las Naciones Unidas; éstas últimas (citando a $\mathrm{A}$. Schelesinger) han servido de fachada y cobertura intemacional a un conflicto esencialmente norteamericano, y el ejército de la coalición no ha actuado bajo la tutela del Eslado Mayor del Consejo de Seguridad previsto por la ONU, sino bajo el mando militar estadounidense. Pequeneces, sin duda, si tenemos en cuenta la importancia de la baza que se ventilaba y el resultado globalmente positivo del conflicto. Quienes deciden los destinos del mundo no se paran en pelillos, ni toman en consideración tales tiquismiquls legales (16-3-91; p. 11). 
En los diarios europeos se entremezclan críticas con remordimientos. Sami-Nair, profesor de la Universidad de París-VIII, se pregunta:" ¿Ha sido esta guerra una guerra del derecho internacional o más bien expresaba la hegemónica voluntad de EE.UU. de arraigarse en una región vital para su economía en declive? La manera en que el presidente Bush gestiona la posguerra y la ofensiva diplomática de Baker en Oriente próximo confirman de hecho la segunda interpretación. EE.UU. es el único actor que obtendrá beneficios inmediatos de la guerra, y la invocación al derecho internacional en la coyuntura fundamentada en el rechazo a la invasión iraqui de Kuwait corresponde, como por azar, a la muy firme voluntad norteamericana de ser la que reparta las cartas de la reorganización del equilibrio del Oriente próximo ...Ni el Consejo de Seguridad, ni ninguna potencia internacional han podido tener peso en el desarrollo de la guerra. El plan francés del 14 de enero y los últimos intentos soviéticos de febrero, aprobados por Alemania, Espana e Italia, no fueron ni tomados en consideración por los EE.UU. Aunque bien es cierto que la irresponsabilidad de Sadam Hussein les fortaleció en este juego" (24-3-91; p. 11).

Se puede adicionar el juicio del papa, Juan Pablo II, quien en su discurso a los siete Patriarcas de Oriente Medio (4-3-91) dijo que la guerra no habia comenzado el 2 de agosto, como afirmaba el sehor Bush, sino que la tentación de hacer dicha guerra era anterior a agosto pasado, cuando el ejército iraqui invadió Kuwait; y que el derecho internacional, a partir de la segunda guerra mundial, ha excluido la guerra como medio apto para resolver los problemas entre las naciones... "La paz del golfo es de algún modo la paz amenazada del mundo entero" (5-4-91; p. 5).

Como se aprecia al leer los informes sobre la reconstrucción, actualmente son los EE.UU. quienes sacan el mayor número de ventajas de esta pretendida guerrra de la ONU. Han acaparado los más jugosos contratos comerciales, mantiene la presencia militar en la zona y de nuevo ha firmado contratos de ventas de armas por $\$ 18.000$ millones con las monarquias petroleras. Por ello Sami Nair comenta": que los EE.UU. y Europa no ocupan el mismo lugar en el equilibrio de fuerzas ni tienen los mismos intereses. El alineamiento de Europa en la guerra al lado de los EE.UU. no debe ocultar el hecho de que los europeos tienen intereses en el Mediterráneo no sólo diferentes, sino opuestos a los de EE.UU".

Estas actuales tensiones entre quienes fueran antes miembros de la trilateral son retomados por I. Sotelo, catedrático de CC. Políticas de la Universidad Libre de Berlín. Bajo el título de "la hora de la verdad" va 
comentando algunas obscuridades subyacentes en todo este proceso... "La segunda mentira -que se trataba de una guerra de Naciones-Unidas para restablecer el orden internacional- contó desde un principio con muy poca credibilidad, que se quebró por completo en las últimas semanas... La cuestión que queda abierta es la de la reorganizacón de las Naciones Unidas para que recupere su verdadera función arbitral y no bélica, entre las grandes potencias y entre éstas y el tercer mundo". A juicio del catedrático berlinés, la intención de toda la operación bélica fue dar una lección a cualquier pais del tercer mundo que aspire a una cierta autonomia o que se salga de las reglas escritas o no escritas. No se aplicó la misma norma a Israel para que se retirara de los territorios invadidos de Golán... "Una gran potencia puede intervenir, anexionar, amenazar con una invasión o minar un puerto extranjero, pero ¿dónde iriamos a parar si todos los pueblos se guiasen por el comportamiento de los poderosos?" (7-3-91, p. 13...).

Todo ello le lleva a concluir que la forma en que se constituyó el Consejo de Seguridad después de la segunda guerra mundial no corresponde a la relación de fuerzas en el mundo de hoy. La Unión Soviética, de gran superpotencia, ha pasado a ser nación dependiente de la ayuda y colaboración occidentales. No se sugiere retirar a los EE.UU. del Consejo de Seguridad, para lograr una mayor igualdad de las naciones miembros, sino ampliarlo con la integración de las dos potencias económicas. Alemania y Japón. No se les puede pedir que asumen sus responsabilidades internacionales sin estar presentes en los órganos de decisión. Las intensidades diferentes con que las naciones europeas han participado en el conflicto y el aparente fracaso de la mediación soviética llevan a concluir que el principal objetivo de la guerra contra Sadam era debilitar el proyecto de la "Europa Unida", asegurar la hegemonia norteamericana en el mundo y en Europa, fortaleciendo un atlantismo que deberia irse desmoronando una vez acabada la guerra fría.

Frente al comentado defetismo de la unidad europea encontramos del otro lado del Atlántico "la gran sonrisa de los Estados Unidos", en expresión de B, Iraburu. El conflicto ha demostrado la capacidad de 84 ejército para vencer tan rápidamente al adversario, y la virtuosidad de su diplomacia para forzar adhesiones o imponer silencios. La gran euforia contrasta con el aún reciente sentimiento de la declinación norteamericana. A la recesión económica se unía el hecho de que Europa ya no necesitaba de los EE.UU. para defenderse de la amenaza sovietica". Somo el único país capaz de proyectar el poder a gran escala "dijo George Schultz. Esto trajo un gran alivio, porque todavla en octubre de 1989 la Casa Banca se preguntaba cómo hacer para que la 
OTAN fuera relevante y mantener la influencia en la nueva Europa. Con el crecimiento de la deuda y de los déficits comerciales se podla leer en los diarios que "Washington se está convirtiendo en una capital de segundo orden; el poder está ahora en Bonn, Tokio y Bruselas. A terminar la guerra fria, la gente empezó a decir que el poder económico iba a reemplazar al poder militar y que iba a ser la era de Alemania y de Japón". Y anade: "este cambio ha quedado pospuesto al menos diez o quince anos a raiz de la victoria del Golfo".

Los EE.UU. han honrado a sus héroes; el Congreso estalló en aplausos cuando G. Bush mencionó a Richard Cheney, Colin Powell y Norman Schwarzkoft". Los soldados de la operación Tormenta del Desierto han logrado más de lo que quizás sospechan. Mientras combatian al enemigo en el extranjero estaban transformando su nación... Nos hemos liberado de una vez por todas del sindrome de Vietnam", anadió Bush el $1^{2}$ de marzo. Pero esto hace temer a algunos que los EE.UU., puedan ser ahora victimas del "síndrome de Irak", fácilmente proclives al uso de la fuerza. El representante demócrata John Lewis advertia: "no vamos a tener siempre la suerte de topamos con enemigos tan incompetentes y tan diabólicos como Sadam Hussein".

El éxito militar, los precios bajos del petróleo y las perspectivas de la reconstrucción del Medio-Oriente han generado un optimismo económico reflejado en el índice Dow-Jones, que creció un $16 \%$ entre el 16 de enero y el 26 de febrero. Otros analistas no lo ven con tanta confianza, entre ellos el Premio-Nobel Paul Samuelson (7-4-91; p. 8). Para estos últimos, con guerra o sin guerra, el pais tendrá que seguir enfrentando la recensión en la construcción, en el automóvil, más la limitación del crédito de parte de la banca lastimada por la crisis inmobiliaria. "La prioridad más urgente ahora es que la economía vuelva a moverse" dijo Bush el 6 de marzo.

Si los EE.UU. han logrado la victoria en la guerra y se confirman como la primera potencia militar, ahora tienen que enfrentar el problema de la paz dentro y fuera de su pais. No sin razón el columnista W. Buckley comenta que "un país capaz de organizar la Tormenta del Desierto debe ser también capaz de mantener la seguridad en el Central-Park y cuando se pueden fabricar Patriotas se debe poder plantar la cara a Sony". Más importante es la observación del ya citado $\mathbf{Z}$. Brzezinski sobre el papel de los EE.UU. en el Medio-Oriente". Lo que me preocupa es que los EE.UU. pueden no estar preparados para asumir las responsabilidades políticas necesarias que emanan de una victoria militar: la creación de una estructura de seguridad en la región completamente nueva, la promoción de una redistribución de la riqueza 
entre los árabes, el avance en el proceso de paz árabo-Israell... los norteamericanos tendremos que asumir la tarea por nosotros mismos $\bullet$ intentar demostrar que la política norteamericana para la zona llegare más allá que la política del garrote; que también tiene componentes constructivos. Esto es ahora un imperativo... Pero la idea de una paxamericana es insuficiente. Por eso creo que hay que darle una definición consistente al nuevo orden mundial. Quizás la palabra orden no sea la mejor, especialmente en el contexto del Medio-Oriente, ya que implica congelar el statu-quo. Pero el mundo necesita un cambio constructivo, no un orden estático. Ahora EE.UU. tendrán que comprometerse más activamente en la creación de un orden pacífico y justo del que hubiera sido de otro modo" (7-3-91; p-4).

En esta entrevista con $Z$. Brzezinski se aprecia una excesiva prepotencia en el ex-asesor militar de J. Carter. Los EE.UU. son y han sido siempre la única superpotencia; la diplomacia soviética ha perdido todo poder de atracción y de convencimiento; los EE.UU. serán los artífices del nuevo orden pacífico y justo. Esta visión nos confirma la tesis que se ha querido probar: la ONU, su Consejo de Seguridad y la Asamblea General se plegaron a los dictados de la superpotencia. Seria bueno que los EE.UU. escuchen otras voces: "vencereis, pero no convencereis". Sobre todo que la guerra por la paz exige revisar y contralegislar conductas pasadas y aun presentes, entre otras el comercio de las armas y sobre todo reorganizar una coalición de naciones donde no haya dominantes y dominados. A este futuro de la paz se le ha llamado "el tablero de la posguerra": la incognita ahora es si los aliados pueden ganar la paz a corto y mediano plazo. A ello nos vamos a referir bajo el tema de la reconstrucción, que de momento presenta rasgos de guerra económica.

\section{La reconstrucción}

Nos referimos en primer lugar a la destrucción física de las naciones afectadas por este contundente conflicto. Antes de iniciarse la invasión de Kuwait la mayoria de paises industrializados, a excepción de Alemania y Japón, presentaban claros indices de recesión económica. entre ellos los EE.UU. Con el conflicto del Medio-Oriente se comienzan a calcular los "dividendos de la guerra". R. Behard (Time Magazine) cree que "la victoria en el Golfo reforzará la economia de EE.UU., pero no deben esperarse milagros". ¿Será la guerra o será la paz quien ayude a la recuperación? Normalmente ha sido la guerra quien estimula la producción creciente de bienes y servicios. Pero esta vez no ha sldo asi, por que la presente guerra, por su brevedad, se ha librado con armas y municiones que se guardaban en el armario. Por ello es la paz 
la que se comienza a ver como la chispa y la catapulta que encienda y proyecte la recuperación. La paz es vista como la nueva medicina que reanime los siguientes miembros del cuerpo económico. Primero, la confianza de los consumidores, que invirtió su trayectoria a partir del mes de febrero". La nación norteamericana ha vuelto a recobrar su confianza en el campo de la batalla del Golfo-Pérsico... La guerra ha demostrado que no tenemos por qué ser comparsa de nadie, que no necesitamos que alemanes y japoneses nos ayuden a conseguir nada"... Realmente, el sindrome de Irak está desplazando al sindrome de Vietnam.

Wall-Street es el segundo miembro reanimado por la paz. El triunfo cotiza, y el indice Dow-Jones sube un $23 \%$ desde la caida de octubre90. Se podía leer en los diarios": esta es la primera guerra popular desde la segunda guerra mundial. Es muy posible que veamos cómo los consumidores to celebran comprando el auto, la televisión o la refrigeradora que habian dejado para mejor ocasión. Esto seguirá así un largo tiempo, convirtiendo la recesión en una recuperación". Si a ello se anade que se acabó el temor del petróleo a \$30-barril y que su precio rondará entre los 15-20 dólares-barril, todo ello beneficiará los gastos del consumidor. También el mercado de la vivienda se podrá reanimar. La mayor parte de las tropas norteamericanas destacadas en el Golfo-Pérsico proceden del sureste de los EE.UU., muy afectado por el estancamiento inmobiliario. Es previsible que en la euforia del regreso, más los bajos tipos de interés a la vivienda, se reanime el sector de la construcción.

El mercado débil por el déficit comercial puede recuperarse con la paz. Aunque el déficit comercial de 1990 superó los $\$ 100.000$ millones, se cuenta con que Kuwait deba comprar mercancias estadounidenses por valor de cientos de miles de millones, dando un fuerte empujón a la balanza comercial. Si la crisis del automóvil comprometía el despido de unos 20.000 trabajadores, con la paz renace el optimismo. Es posible que Kuwait deba sustituir unos 100.000 automóviles y camiones en 1991. Con el alto al fuego también el turismo se reanima; las agencias de viajes ven crecer las reservas para viajes nacionales e internacionales a medida que las companias europeas renuevan sus vuelos a Tel-Aviv... Se comenta que con la paz el mayor beneficio económico es que se reanimará la agresividad y competitividad empresarial por encima de la técnica japonesa.

Ante este enfoque nacionalista de optimismo económico vale la pena preguntarse si todo esto se logrará a cambio de una guerra destructiva de vidas, recursos y riqueza de paises extranjeros. Sangre por 
petróleo y recuperación por destrucción. Y todavia queda "el reparto del botín: EE.UU. se hace con el $70 \%$ de los primeros contratos para la reconstrucción de Kuwait" (10-3-91; p. 15). Si la liberación de Kuwait costó $\$ 50.000$ millones, la reconstrucción de este devastado pais ascenderá a más de los $\$ 200.000$ en los próximos 10 anos. A la guerra militar sucede rápidamente la guerra de las empresas por acaparar toda serie de contratos, porque todo está destruido desde hospitales hasta los pozos de petróleo. "Esto nos va a proporcionar una lista casi ilimitada de trabajo rentable. Es una mina de oro potencial". Al igual que en cualquier campo de batalla los EE.UU. se están llevando la mejor parte, con ausencia notoria de alemanes y japoneses. Los técnicos estadounidenses se han hecho con el $70 \%$ de los contratos preliminares en los tres primeros meses: sofocar incendios en los pozos de petróleo y restablecer el agua y la electricidad con contratos superiores a los $\$ 500$ millones. El cuerpo de ingenieros del ejército de los EE.UU. recibió un contrato de $\$ 46$ millones para realizar la evaluación de los danos. Hay que apagar 500 de los 1.000 pozos petrolíferos a un costo de unos $\$ 15.000$ millones en los próximos cinco anos. Los grandes beneficiarios serán los grandes de la construcción y de la proyección petrolifera. Por su parte el gobierno de Washington ha presionado a Kuwait para que otorge a los EE.UU. un papel destacado en la reconstrucción. Un especialista, que participa en esta primera fase de la reconstrucción, afirma que "Bush quería estar seguro de que se tomaban todas las iniciativas para asegurar a los EE.UU. una parte sustancial de los negocios". Otros paises han comenzado a reclamar su parte proporcional, quedando Inglaterra en segundo lugar. Una empresa británica recibió de Kuwait un contrato de $\$ 100.000$ millones para limpiar los escombros de la guerra.

Por lo que hace a las empresas francesas sólo han recibido buenas promesas de momento. "Kuwait considera que Francia es un aliado firme y estamos dispuestos a conceder contratos a todos los miembros de la coalición". Arabia les ha suministrado alimentos por $\$ 80$ millones, ha hecho ofertas para el suministro de cemento, mientras que Egypto espera facilitar abundante mano de obra. Kuwait cuenta con suficientes recursos propios además de la garantía del petróleo; venderá una parte de los $\$ 300.000$ millones invertidos en valores extranjeros y no tendrá dificultad en obtener nuevos préstamos.

Caso distinto es Irak, que si bien dispone de la segunda reserva de petróleo en el mundo, se hallaba con una deuda pendiente de $\$ 70.000$ millones y más, agravada por el subsiguiente embargo. Su destrucción ha sido aun mayor que la de Kuwait, quedando por resolver el problema de las reparaciones por danos de guerra. Quienes vayan a 
tomar la decisión harian bien en releer el "how to pay for the war" de J. $M$. Keynes, escrito con ocasión de las reparaciones de guerra impuestas a la Alemania de post-guerra, a fin de no provocar otro naclonal-socialismo con su Hitler de Irak.

Detalle curioso: las dos superpotencias económicas, Alemania y Japón, se hallan ausentes en este reparto del botín. Alemania occidental está muy atareada con la reconstrucción tecnológica y ecológica de la anexionada Alemania oriental. El incremento de impuestos sobre la población occidental, equivalente a la dote pagada para sostener la guerra del Golfo, se dedicará a la reconstrucción de la zona oriental. En Alemania están pasando de la euforia de la unificación a las dificultades de la reconstrucción, y esto puede frenar el crecimiento del gigante europeo. Por su parte, los japoneses están resignados a perder negocios en favor de los paises que participaron en la lucha, con la esperanza de que sean llamados para reparar equipos que ellos habian provisto. Confian en que se les solicitarán algunos préstamos financieros... La moraleja es que la reconstrucción beneficiará a quienes llevaron la guerra al Medio-Oriente; la pregunta es: ¿quiénes llevaron la guerra construirán ahora la paz?

\section{v. La reconstrucción de la paz}

Como indicaba el Secretario General de la ONU no basta derribar el muro de Berlín para iniciar la paz entre el Este y el Oeste, si al mismo tiempo se refuerza el muro de la pobreza entre el Norte y el Sur. La guerra fría, con sus inimaginables costos que endeudaron a las superpotencias, tenia un aspecto positivo. Esas armas tienen tal poder destructivo que nadie osaria utilizarlas, porque en expresión de $M$. Gorbachev no habria ni vencedores ni vencidos, sino sólo desaparecidos. Mientras que las superpotencias continúan estos meses el diálogo para el desmantelamiento de estas y aquellas ojivas nucleareas, no existe todavia un diálogo concertado, dentro o fuera de la ONU, para controlar las otras armas convencionales, que son las realmente destructivas porque son las que si se usan. Una de las críticas al Consejo de Seguridad de la ONU es que sus cinco miembros permanentes (EE.UU., URSS., Francia, Gran Bretana y China) sean quienes ocupan los cinco primeros puestos en el comercio mundial de armamento; asl como es irónico que al mismo tiempo que se firma el cese al fuego en el Medio-Oriente, los EE.UU. hayan firmado contratos de suministros de armas a paises de la zona por valor de $\$ 18.000$ millones. ¿Será éste un componente disuasivo de la pax-americana?

Siendo tan resquebradiza la causa de la paz y tan espontáneo el 
resurgimiento de nuevas guerras hay que buscar las causas y $108 \mathrm{mo}$ todos preventivos. S. Hoffman, de Harvard, cree "que el mundo puede vivir una situación aún más caótica que la de la guerra fria". Inicla su ponencia con la siguiente reflexión. "Una de las lecciones es que más vale un gramo de prevención que una tonelada de castigo. Si en un mundo de regimenes inestables, fronteras contestables, conflictos étnicos y de resurgir religiosos, cada acto de agresión requiere la movilización de 750.000 hombres que crucen los mares para enfrentarse a alborotadores armados hasta los dientes, habrá pocos momentos de seguridad colectiva. La guerra del Golfo puede ser una excepción en to que respecta a la violación de Sadam del principio fundamental del orden mundial: la integridad territorial y la independencia política de los estados, que fue especialmente fragante por los altos intereses en juego. Necesitamos evitar, más que reprimir la agresión y la tentación de los Estados de exportar sus dificultades internas. Requerirá una acción colectiva en cuestiones que han recibido una desatención maligna o benigna respectivamente" (7-3-91; p. 3).

La desatención maligna o benigna se aplica en el caso de Irak. La sociedad internacional prestó atención a la guerra Irak-Irán, la guerra contra nuestro enemigo, pero cerró los ojos ante la matanza de los kurdos realizada por Sadam Hussein y la destrucción que llevó a cabo de la oposición. Por ello Hoffman advierte: "La circunstancias que conducen a una dictadura y a una violación de los derechos humanos a gran escala en un pais pueden llevar -más tarde o más tempranoa la búsqueda de enemigos foráneos. Uno de los mejores mecanismos de predicción del comportamiento sigue siendo la forma con que un Gobierno trata a su propio pueblo".

Sin embargo la paz y la seguridad quedan comprometidas mientras "la legislación internacional y la ONU permanezcan ancladas en una irreal distinción entre los asuntos externos e internos. Ambos tienen en cuenta el comportamiento interno de los Gobiemos sólo cuando se produce un atentado a las normas internacionales y regionales establecidas para la protección de los derechos humanos". Esta normativa lleva a la indiferencia o a la tolerancia de violaciones por parte de un pais aliado o de quien se puede obtener algun tipo de beneficio. Tal el caso de Irak ante del conflicto. Otro mal ejemplo sivió para acabar una buena conclusión del derecho internacional. Las políticass de segregación racista del Gobierno blanco de Surárica dio por resultado las lerribles intervenciones en Angola y Mozambique; los derechos conculcados en un pais tuvieron repercusiones internacionales. S. Hoffman concluye y aconseja. "Ha llegado el momento de que se generallce ol 
principio que las Naciones Unidas han aplicado sólo a Suráfrica: ningún Estado podria poder alegar que la actitud con la que se trata a sus cludadanos es un derecho de soberania, si esa actitud puede crear tensiones internacionales". A modo de ejemplo el autor cita que estas repercusiones las hemos visto anteriormente cuando la represión nacional soviética favoreció la represión de los regimenes comunistas de la Europa del Este; las consecuencias políticas y eocnómicas están a la vista.

Con ello llegamos no sólo a la revisión de la normativa sino a la reestructuración de los miembros componentes de las Naciones Unidas". Pero como la ONU no es más que una asamblea de Gobiernos y como muchos de ellos tienen un cadáver en su armario, ¿podemos esperar realmente que se enciendan sefales de advertencia acompanadas por una reacción colectiva cada vez que se produzca una violación de los derechos humanos en paises cuya posición, recursos, conexiones o lideres puedan poner en peligro la paz internacional?"

No puede haber un relanzamiento del papel diplomático de las $\mathrm{Na}$ ciones Unidas, sin un esfuerzo de todos los paises, grandes potencias y paises vecinos, que ganarian más con un acuerdo y perderian más con una guerra. La ONU no puede actuar sin un grupo dirigente, diverso en cada circunstancia por la enmaranada complejidad de cada caso. Esta es la lección que se debe sacar del conflicto en el Medio-oriente, donde además de las tensiones palestino-israelies, los nacionalismos y mesianismos religiosos, puede pervivir la simpatia por el derrotado Sadam Hussein al considerarlo el campeón de la resistencia a los EE.UU. y al Occidente que son vistos, en parte como imperialistas y en parte con una doble moral hacia el Medio-Oriente.

Otra causal de estos conflictos es la balanza de pagos de las economias occidentales. Es urgente proceder a una legislación y control del comercio de armamento. No basta el congelamiento de misiles nucleares mientras prosiga el comercio de las otras armas que son de hecho más letales. No es que el primer congelamiento sea perfecto, puesto que hay paises en vias de producción o de compra, encabezando la lista Israel... Sin embargo, un primer paso sería la restricción de la venta de tecnologia militar avanzada, material nuclear y equipos para la producción de armamentos bactereológico-quimico, producidos por empresas privadas, con el consentimiento o tolerancia de sus Gobiemos y con el visto bueno de sus balanzas de pagos... El nuevo orden intemacional no puede surgir de este lucrativo comercio de armas. ¿La paz y la seguridad podrán ser arbitradas por esta clase de Gobiernos? 
Adolfo Suárez, expresidente de la Internacional Liberal y Progresista, recuerda que esta institución se dirigió al Secretario General de la ONU, urgiéndole a promover una convención internacional para la restricción del comercio de armamento, que someta todas las exportaclones de armas a un estricto control de las autoridades gubernamentales; que establezca un registro internacional de las ventas de armas; prohiba la exportación de armas a regiones sometidas a tensiones militares crónicas; autorice a suspender esa prohibición sólo en casos en que la ONU aprecie una situación de legítima defensa; prohiba en todo caso la exportación de armas químicas-biológicas, asi como la tecnología y la asistencia técnica para la producción de armas de destrucción masiva; y por último, límite la concesión de créditos estatales para la compra de armas... Realmente, aun estamos bien lejos de estas premisas intemacionales. Resulta tristemente contradictorio el celo y la vigilancia que los países del Norte ponen en erradicar el tráfico de la droga desde el Sur hacia el Norte, y la tolerancia y connivencia que prestan al comercio de las armas descendientes del Norte para el Sur. Por lo visto, para las grandes potencias sólo tienen valor su balanza de pagos y su higiene o seguridad social. También los paises pobres tienen los mismos problemas cien veces más agudos.

Con el esperado fin de la guerra fría y la disolución de los bloques milltares e ideológicos, el centro de la reflexión y de la preocupación se traslada a la división de la humanidad en paises ricos y pobres o conflicto Norte-Sur. Los paises del hemisferio-Norte no pueden tranquilizar sus conciencias y despreocuparse de estos problemas por el simple hecho de que los paises del Sur lograron sus independencias nacionales en la primera mitad del siglo. En las raices del conflicto Golfo-Pérsico encontramos el colonialismo e imperialismo económicos disimulados con independencias nacionales. No se ha tomado en cuenta este problema ni el de la cultura islámica, que en su tiempo fuera la cuna de las civilizaciones. Es triste que para buena parte del Occidente esos países sean importantes, hoy y en 1970, sólo por el petróleo. Tampoco supone gran toma de conciencia de todos estos problemas del Sur el ofrecerles como solución los brazos abiertos de la economia de mercado del Norte. Como las leyes de ese mercado son las "fuerzas" de la oferta y de la demanda volvemos a otro estilo de guerra que destruye lentamente. De acuerdo a reciente informe del Banco Mundlal 1.200 millones de personas viven en condiciones de extrema pobreza, y la cifra se queda muy baja. Para final de siglo más de 2.000 millones de personas se hacinarán en los suburbios de 90 ciudades de palses subdesarrollados.

Adolfo Suárez concluye: "Un nuevo orden internacional que Impida 
al menos la agudización de los desequilibrios actuales es una exigencia de la moral internacional, y por lo tanto del humanismo liberal, empehado siempre en buscar nuevas cotas de dignidad y desarrollo humano dentro de una sociedad cooperativa". Si fracasó la mediación política de $M$. Gorbachov en la crisis del Golfo-Pérsico, ante la prepotencia norteamericana, quedan siempre en pie las tres grandes tesis de su Perestroika. Todos los paises del mundo somos interdependientes y estamos interrelacionados, de suerte que los intereses de unos no puedan lograrse sin salvaguardar los intereses de los otros. $Y$ puesto que estos intereses son distintos dialoguemos, no con animosidad, sino con espíritu de colaboración. Dialoguemos para la colaboración porque si todos los paises tienen sus problemas, los paises en desarrollo los tienen cien veces más. "Oueremos que la libertad reine finalmente en todas las partes del mundo en el próximo siglo. Queremos competencia pacífica entre los diferentes sistemas sociales para desarrollar y alentar la cooperación mútua antes que las confrontaciones y la carrera armamentistica. Queremos que los pueblos de cada país disfruten de la prosperidad, la salud y la felicidad". Asi reza el epilogo de Perestroika.

Adolfo Suárez, en su ponencia "Reflexiones para después de la guerra", traduce así las tesis de Perestroika: "1) No hay soluciones simples para problemas complejos. La libertad, la seguridad o el bienestar requieren una difícil combinación de elementos pequenos y grandes, nacionales e internacionales, centralizados y descentralizados. 2) Favorecer el internacionalismo en el planteamiento, debate y resolución de los problemas con que hoy se enfrenta el mundo. Ello implica contribuir a fortalecer o a mejorar los organismos internacionales, en particular aquellos que tienen como objetivo la paz, la cooperación y el desarrollo económico y social, desde la convicción de que los actuales problemas de la humanidad sólo pueden ser resueltos a través de la cooperación internacional. 3) Contribuir a crear una legislación intemacional que vaya más allá de ser mero instrumento de ordenación de relaciones y de distribución de competencias entre Estados Soberanos... El derecho internacional tendrá que encontrar su sentido en el mayor énfasis de la dimensión de cooperación. La idea misma de comunidad interanacional, además de aspiración política y moral, debe ser la columna vertebral desde la que tendría que configurarse y comprenderse el derecho internacional contemporáneo" (3-3-91; p. 1314).

Estas laudables y necesarias recomendaciones contrastan con to que el escritor Mario Benedetti describe como "el eclipse de la solidaridad". Lo que más sentimos es "la trepidante derechización experimen- 
tada urbi et orbi por los estamentos políticos y los medios comunicantes, que ha generado como consecuencia la soberbia de los vencedores y la inhibición de los vencidos". Las comunidades del Este no están cómodas ni en el primero ni en el segundo mundo; pero el gran perdedor, como siempre, es el tercer mundo. "Orgulloso de su bienestar, de sus adelantos técnicos, de su jet-set, de sus banqueros, el engreído Noroeste o primer mundo ha adoptado un talante nítidamente egoista y ha convertido ese rasgo en la gran novedad en curso... Occidente se ve hoy aquejado de una alarmante mezquindad, y el sindrome de insolidaridad dócilmente adquirido puede llegar a ser tan grave como el otro sida" (9-1-90; p. 15).

A juicio de Benedetti sufren con este sindrome de insolidaridad las recién adoptadas sociedades del Este, a quienes el Oeste les comienza a mirar con recelo: disidentes del régimen comunista reclaman un sitio en el nirvana del mercado de consumo que les habia prometido la publicidad occidental, y encuentran que el pais anfritrión los recibe con aires de superioridad. En el Foro de la Soborna (París: febrero-1990) B. Gemerek (de Solidaridad) se refería a los comportamientos xenófobos y de miedo respecto del pobre europeo oriental que llama a la puerta del occidente opulento". Un ejemplo preocupante es la situación de los alemanes orientales "anexionados" recientemente a la Alemania Federal...

A este propósito, en el artículo de Benedetti hay dos referencias Interesantes, referidas al mundo eclesiástico. Observa el autor que la autoridad eclesiástica se resiente, en declaraciones recientes, de la disminución de fieles y de sacerdotes, cada vez más aquejados de incurable soledad. La autoridad eclesiástica "parece no haber advertido que la actual religión del Oeste ampliado es el sacramento-dinero, y que algunos devotos de este nuevo culto son capaces no sólo de crucificar nuevamente a Cristo, sino también a la patria, al párroco, la madre y la tercera esposa". Cita a un poeta mexicano: "Ya somos todo aquello coritra lo que luchamos a los veinte anos". La insolaridad es contagiosa y la solidaridad es una palabra tan larga e incómoda que ni siquiera cabe en los poemas modernos.

También la autoridad eclesiástica debe meditar el tema de la solldaridad en la línea de cooperación y del desarrollo de los pueblos. "La propia Iglesia restringe su solidaridad a la parcela de las oraciones, pero deja caer sus estigmas, presiones y amenazas sobre la incormoda "teología de la liberación", que corrobora con hechos su saludable obsesión de que el cristianismo se cristianice. En realidad, Cristo y Marx están cada vez más solos en su propuesta de solidaridad... Estamos 
en pleno jubileo del capitalismo, y sabemos que el capital sólo es solidario (aunque no siempre, Japón dixit) con el capital). Hay, sin embargo, otra tradición menos voceada, pero más profunda: que los pueblos suelen ser solidarios de los pueblos". Luego de meditar estos entreverados testimonios volvemos a la pregunta inicial: ¿un nuevo orden internacional y cuál?

Todo lo aqui comentado ha sido escrito en referencia al conflicto del lejano Medio Oriente. Quizás alguna página nos ayude a entender mejor la realidad de nuestro istmo y de nuestro pals. En reciente viaje por Honduras y El Salvador, el general Colin Powell se dejo decir, por culpa de traductor: "si es preciso, los invadiremos". Desde luego que este general no pesó las serias consecuencias de semejante invasión, ni nuestra capacidad y tolerancia: ¿dónde pensarla meter a los $\mathbf{7 5 0 . 0 0 0}$ miembros de su ejército? 